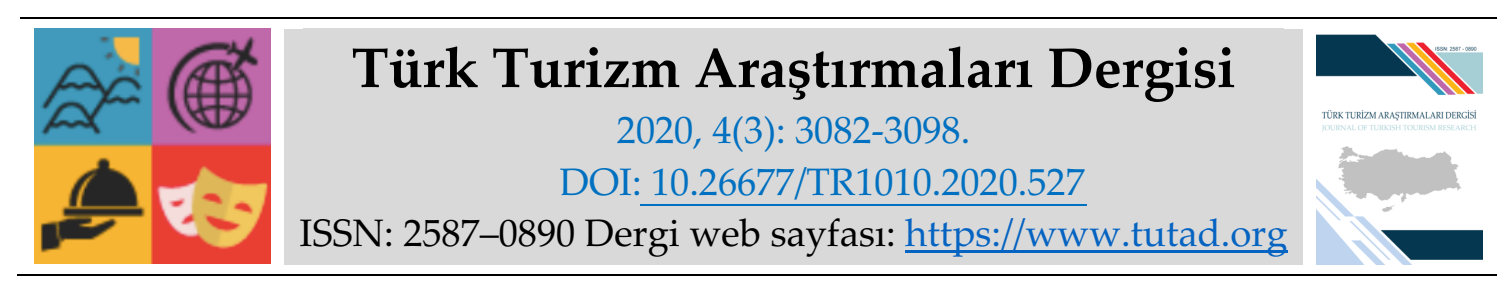

KAVRAMSAL MAKALE

\title{
Yiyecek-İçecek Sektöründe Sürdürülebilirlik ve Yenilikçi Yaklaşımlar
}

Arş. Gör. Demet TAŞ, Kastamonu Üniversitesi, Turizm Fakültesi, Kastamonu, e-posta: demettas@kastamonu.edu.tr

ORCID: https://orcid.org/0000-0003-0691-5562

Dr. Öğr. Üyesi Emine OLUM, İstanbul Medipol Üniversitesi, Güzel Sanatlar Tasarım ve Mimarlık Fakültesi, İstanbul, e-posta: eolum@medipol.edu.tr

ORCID: https://orcid.org/0000-0002-7188-817X

Öz

Doğal kaynakların verimli kullanımının öneminin artmasıyla birlikte, yenilenebilir ve etkin kaynak kullanımı elzem hale gelmiştir. Küresel tehdit unsuru haline gelen sera gazı emisyonu, yeşil alanların tahribi, bilinçsiz ve aşırı tüketim gibi faktörler yakın gelecek için endişe verici bir hal almıştır. Bu tarz olumsuzluklar karşısında çözüm olanakları üzerinde yoğunlaşan bu derleme çalışmasında yiyecek içecek sektöründeki alternatif ve yenilikçi sürdürülebilir uygulamaların öneminin vurgulanması amaçlanmıştır. Bu amaç doğrultusunda, konuyla ilgili ulusal ve uluslararası literatür taraması yapılmıştır. Yapılan detaylı literatür taraması ile yiyecek-içecek sektöründeki kullanılabilecek internet destekli yenilikçi ekipman ve akıllı telefon uygulamaları tanıtılmıştır. Yeşil restorancılık faaliyetleri, atıkların biyoyakıt olarak değerlendirilme olanakları, gıda bankaları, dijital mutfak aletleri ve üç boyutlu gıda yazıcılar bu bağlamda incelenmiştir. Bu çalışmada derlenen bilgiler ışığında yiyecek içecek sektöründe atıkların azaltılması ve kaynakların bilinçli kullanımı yoluyla uzun vadede önemli kazanımlar sağlanabileceği öngörülmektedir.

Anahtar Kelimeler: Akıllı Mutfak Uygulamaları, Nesnelerin İnterneti, Dijital Teknolojiler, Yeşil Restorancilik.

Makale Gönderme Tarihi: 22.04.2020

Makale Kabul Tarihi: 07.07.2020

\section{Önerilen Atıf:}

Taş, D. ve Olum, E. (2020). Yiyecek-İçecek Sektöründe Sürdürülebilirlik ve Yenilikçi Yaklaşımlar, Türk Turizm Araştırmaları Dergisi, 4(3): 3082-3098.

(c) 2020 Türk Turizm Araştırmaları Dergisi. 


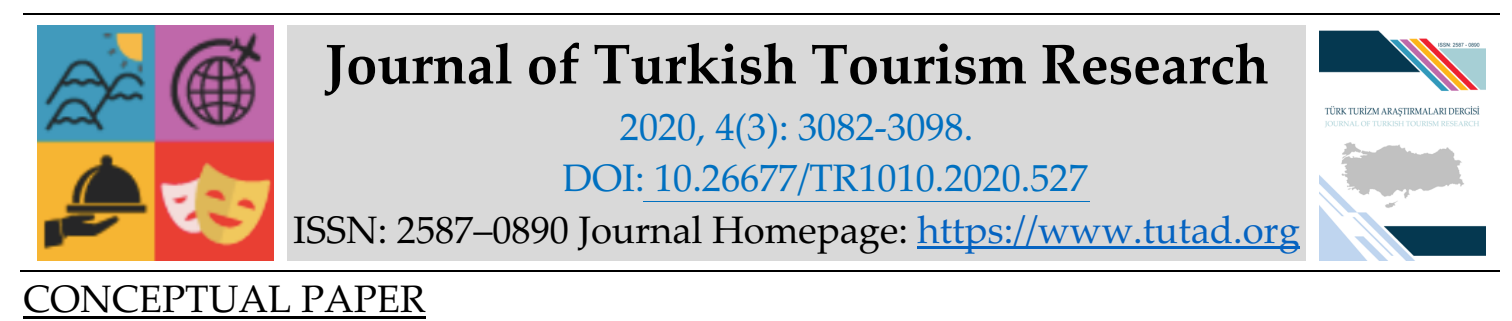

\author{
Sustainability and Innovative Approaches in Catering and Food and Beverage \\ Industry
}

Research Assistant Demet TAŞ, Kastamonu University, Faculty of Tourism, Kastamonu, e-mail: demettas@kastamonu.edu.tr ORCID: https://orcid.org/0000-0003-0691-5562

Assistant Prof. Dr. Emine OLUM, İstanbul Medipol University, Faculty of Fine Arts, Design and Architecture, İstanbul, e-mail: eolum@medipol.edu.tr

ORCID: https://orcid.org/0000-0002-7188-817X

\begin{abstract}
In today's world the importance of efficient use of natural resources has increased and the use of renewable resources in an effective way has become essential. Factors such as greenhouse gas emissions, destruction of green areas, over-consumption and unconscious use of resources have become a global threat for the near future. In the present review, which focuses on the solution possibilities for such negativities, it is aimed to emphasize the importance of alternative and innovative sustainable practices in the food and beverage industry. For this purpose, national and international literature review was conducted regarding sustainability. With the detailed literature review, innovative internet-supported equipment and smartphone applications that can be used in the food and beverage industry were introduced. Green restaurant activities, the possibility of use of food wastes as biofuels, food banks, digital kitchen appliances and 3D food printers were examined in this context. In the light of the information reviewed in the present study, it is seen that significant gains can be achieved in the long-term period through the reduction of wastes and the conscious use of resources in food and beverage industry.
\end{abstract}

Keywords: Smart Kitchen Appliances, Internet of Things, Digital Technologies, Green Restaurant Received: 22.04 .2020

Accepted: 07.07.2020

\title{
Suggested Citation:
}

Taş, D. and Olum, E. (2020). Sustainability and Innovative Approaches in Catering and Food and Beverage Industry, Journal of Turkish Tourism Research, 4(3): 3082-3098.

(C) 2020 Türk Turizm Araştırmaları Dergisi. 


\section{Gíriş}

Dünya genelinde gıdaların adil olmayan dağılımı ve kaynakların aşırı kullanımı, gelecek nesiller için endişe verici bir hal almaktadır. Bugün tüm insanlara yetecek kadar gida üretilmesine rağmen milyonlarca insan açlık ve kronik olarak yetersiz beslenme (malnütrasyon) yaşamaktadır. Yeterli ve güvenilir içme suyu sıkıntısı da önemli sağlık problemlerini beraberinde getirmektedir (Coff, Korthals ve Barling, 2008). Her yıl 12 milyon çocuk açlıkla ilgili hastalıklardan dolayı hayatını kaybetmektedir (Sarıkoca ve Daşlı, 2016). Her yıl milyarlarca kilo gıda israf olurken yetersiz beslenme sonucu ölen ve ciddi rahatsızlıklar yaşayan insanların sayısı önemli bir çelişkiyi ortaya koymaktadır (Özdilek-Dölekoğlu, Gün ve Giray, 2014).

Mevcut durumun gelecek nesiller için daha da endişe verici bir hal alacağı öngörüldügünden eldeki kaynakları adil bir şekilde kullanmak ve sürdürülebilir yaşam modeline geçmek zorunlu hale gelmektedir. Modern dünyada aşırı nüfus artışı, sanayileşme, doğal alan tahribatları, hava su, toprak kirliliği gibi nedenlerden ötürü biyoçeşitliliğin zarar görmüş olması sürdürülebilir uygulamalara olan ihtiyacı gözler önüne sermektedir (Gowdy ve McDaniel, 1995; Ponting, 2008; Keleş, Hamamcı ve Çoban, 2009).

Sürdürülebilirlik kavramı, uzmanlık alanlarına göre farklı tanımlar barındırmaktadır. Ekonomi bilimi için yaşam standartlarının belirli bir düzeyde tutulması gerekliliği iken, çevrebiliminde ekolojik hayatın korunmasıyla ilgili tanımlamalar söz konusudur (Yeni, 2014). Sürdürülebilirliğin ekosistemin devamlı olarak etkin bir şekilde işleyebilme yeteneği olarak ifade edildiği (Chapin, Torn ve Tateno, 1996) süresi belli olmayan bir döngüyü sürdürebilme kapasitesi (Yavuz, 2010) olduğu ve insanoğlunun yükünü taşıyabilmek adına yeryüzünün kapasitesini muhafaza etmeyi (Salomone, 2014) amaçladığı belirtilmiştir. Yiyecek-içecek sektörü söz konusu olduğunda sürdürülebilirlik, gıda atıklarının azaltılmasından etkili enerji kullanımına kadar geniş bir yelpazede değerlendirilmektedir. Sürdürülebilirlik yalnızca mevcut kaynakları korumak değil, aynı zamanda akılcı ve sorumlu bir şekilde üretmek anlamına gelmektedir. Gıda sektöründeki üretim, işleme, depolama gibi aşamalarda meydana gelen gıda atıklarının her geçen yıl artması nedeniyle sürdürülebilirlik gıda sektöründe üzerinde durulması gereken önemli bir kavram haline gelmiştir. Kısaca özetlemek gerekirse sürdürülebilirliği gıdaların hazırlanması, işlenmesi, depolanması ve tüketimi esnasında ortaya çıkan ekolojik ve ekonomik zararı en az düzeye indirme girişimi olarak tanımlayabiliriz.

Tüketicilerin gida tüketim eğilimlerini belirleyen en önemli etmenler fiyat, kolay ulaşım ve kalitedir. Ancak artık tüketicilerin önemli bir kısmı sürdürülebilir ve doğa dostu üretim şekillerini ve ürünleri tercih etme eğilimi göstermektedir (Atrek ve Madran, 2017). Sektörde yer alan baskı ve rekabet ortamı, işletmeleri tüketicilerin neye önem verdiğini daha iyi anlamaya ve bu yönde stratejiler uygulamaya yönlendirmektedir (Yücenurşen, 2019). Bu bağlamda rekabet ortamındaki mücadelenin bir diğer ayağı da sürdürülebilirlik olmaktadır.

Sürdürülebilirlik ilkelerine uygun üretim yapan gıda firmaları dikkat çekici bulunmaktadır. Sürdürülebilirlik, aynı zamanda işletmenin de sürdürülebilirliğini sağlamaktadır. Yani sürdürülebilir hedefleri olan işletmeler değişen sosyal, fiziksel ve ekonomik koşullara daha iyi adapte olmaktadır (Freeman, 2011). Bunun yanında işletmeye uzun vadede ekonomik anlamda getirisi olabilecek bir takım tasarruf faaliyetlerini de içine almaktadır.

$\mathrm{Bu}$ çalışmada sürdürülebilir strateji ve hedefler doğrultusunda konu, yiyecek içecek sektörü açısından ele alınmaya çalışılmıştır. Hem evlerde hem de endüstriyel mutfaklarda uygulanan ve uygulanabilecek sürdürülebilir strateji ve yöntemlere dikkat çekilmiştir. Diğer yandan yeşil restorancılık faaliyetleri ve mutfaklarda tasarruf mekanizmasıyla çalışan yenilikçi ekipmanların tanıtılması ve fonksiyonlarının açıklanması amaçlanmıştır. 


\section{GIDA SEKTÖRÜNDE SÜRDÜRÜLEBILİRLIKK}

İklim değişikliği, göç, artan dünya nüfusu, adil olmayan gıda dağılımı, yetersiz beslenme, obezite gibi birbiriyle ilişkili sorunların çözüm yollarından biri de sürdürülebilir yaşam ve üretim modelleridir. Nüfus artışı beraberinde enerji, gıda ve su talebinin arttırmasını getirmektedir (Bazilian, Rogner, Howells, Hermann, Arent, Gielen, Steduto, Mueller, Komor, Tol ve Yumkella, 2011). Gıda ihtiyacının artması ile küresel ölçekte büyüyen gıda sektörü, çevre kirliliği, toprakların verimsizleşmesi, uzak bölgelere yapılan nakliye şartlarının getirdiği ekolojik olumsuzluklar ve aşırı su tüketimi gibi çevresel tahribatlara sebep olan uygulamalardan sorumludur. Bu nedenle özellikle yiyecek-içecek sektöründe doğal kaynakların sürdürülebilir ve verimli bir şekilde kullanılması, sektörün olumsuz çevresel etkilerinin sınırlandırılması açısından önemlidir (Axelos, Basinskiene, Darcy-Vrillon, Ruyck, Pou, Salaseviciene ve Huttunen, 2018).

Birleşmiş Milletler'in Ekim 2018'de düzenlediği Hükümetler Arası İklim Değişikliği Paneli'nde yayınladığı özel raporunda dünyanın küresel ssınmanın etkilerini düşünüldüğünden çok daha erken hissedeceği görülmektedir. Dolayısıyla panelin vurgu noktası, toplumun bir an önce tüm alanlarda hızlı ve kapsamlı değişikliklere gitmesi gerektiği olmuştur. Durum gıda endüstrisi açısından irdelendiğinde tarımsal faaliyetlerin küresel sera gazı emisyonlarının \%30'una tekabül ettiği tahmin edildiğinden, iyileştirmeye ihtiyaç duyulan alanlar arasında gıda endüstrisi ilk sıralarda yer almaktadır (United Nations, 2018).

Yiyecek-içecek sektöründeki girdi-çıktı dengesinin sağlanması, etkin üretim, depolama ve dağıtım kanalları için sürdürülebilir uygulamaların üzerinde durulması gerekmektedir. Özellikle restoranlar ya da hazır yemek şirketleri gibi organik atıkların fazla miktarda oluştuğu işletmelerde atıkların enerji olarak geri dönüşümünün sağlanması etkili bir yöntemdir. Ayrıca, son kullanma tarihi yakın ürünlerin çeşitli dijital kanallar aracıllı̆ıyla ya da doğrudan bazı kurum ve ihtiyaç sahibi kişilere iletilmesi ile gıda israfının önüne geçilmektedir.

\section{Dijital Teknolojiler ve Nesnelerin İnterneti}

Sürdürülebilir gıda üretiminde sektörün karbon ayak izini azaltmaya yönelik yenilikçi teknolojilerin geliştirilmesi söz konusudur. Teknolojinin günlük hayatımıza hâkim olduğu son yıllarda, özellikle mutfak aletlerinin teknolojiyle uyumu sonucunda yemek pişirme, saklama ve dağıtım şekillerine yenilikçi yöntemler eklenmiştir.

İnternet özellikle son yirmi yılda iyi bir noktaya ulaşarak ekonomik ve sosyal hayatı değiştirme ve güçlendirme özelliğine sahip olmuştur (Guo, Zhang, Wang, Yu ve Zhou, 2013). Bilgi-işlem teknolojisindeki yenilikler internet kullanıcılarının her geçen gün artmasıyla beraber günlük hayatı inanılmaz kolay hale getirmiştir (Kiritsis, 2011). Dijitalleşen dünyadaki en son yeniliklerden biri de nesnelerin interneti kavramıdır. Nesnelerin interneti, insan hayatına büyük yenilikler getiren, bilgiyi kimsenin tahmin edemeyeceği şekilde aktarmayı sağlayan bir platformdur (Chatterjee, Kumar, Khari, Hung ve Le, 2018). Nesnelerin interneti, nesneler arasında ya da nesneler ve kişiler arasındaki iletişim ortamını sağlamaktadır (Haller, 2010). Nesnelerin interneti sayesinde, internete bağlı mekanizmalar dışardan fiziksel bir talimata gerek duymadan gerekli fonksiyonları yerine getirmektedir. Nesnelerin internetinin hedefi, çevredeki nesnelerin neyin sevildiğini, neyin istenildiğini ve neye ihtiyaç duyulduğunun anlaşılmasını sağlayarak, açık talimatlara gerek duyulmadan direk etkileşim ortamını sağlamaktır (Hong, Kim, Ha, Bae, Park, Jung ve Kim, 2010). Nesnelerin interneti teknolojisinden faydalanarak birçok dijital mutfak ürünü geliştirilmiştir. Bu teknoloji ile ekipmanlar internetin bağlı olduğu birer yapay zekâ gibi hareket etmektedir.

Nesnelerin interneti sayesinde, internet ile etkileşime geçen nesnelerin daha hızl, üretken ve 
tasarruf mekanizmasıyla çalışması öngörülmektedir. Örneğin özellikle son zamanlarda artan ekmek israfının önüne geçilmesi için tasarlanan mekanizma sayesinde fırınlarda satılmayan fakat yenilebilir durumda olan ekmekler atılmaktan kurtarılmaktadır. Satılmamış ekmeğin durumunu tespit etmek için foto akustik etki kullanarak ekmeğin son kullanma tarihini tahmin eden akıllı bir mekanizma geliştirilmiştir. Bu akıllı mekanizma, 2 ayrı bölmeli ahşap bir kutudan oluşmaktadır. Her bölmede ekmek tutmak için birer tepsi yer almaktadır. Lazer ışını ekmeğe gönderilir ve yayılan ses dalgaları nesnelerin interneti sensörlerine bağlı bir mikrofon tarafından algılanır. Son kullanma tarihi, yeri, miktarı ve türünü içeren ekmek bilgileri android bir bulut sisteminde saklanır. Böylece oluşan arz (fırınlar) ve talep (STK, toplum merkezi vb.) arasında etkileşim sağlanmaktadır (www.instructables.com). Bu teknoloji ile benzer birçok akıllı sistem geliştirilerek işletmelerdeki ve evlerdeki israfın önüne geçilmesi amaçlanmıştır.

\title{
Akıllı Öğütücü
}

Whirlpool Corporation tarafından gıda atığı üzerine yapılan bir araştırmaya göre, Amerika Birleşik Devletleri'ndeki ortalama bir aile, her yıl $181 \mathrm{~kg}$ gıda atığına sebep olmaktadır. Gıda atığını minimum düzeye indirmeyi sağlayan yeni bir teknoloji olan akıllı öğütücü (Zera Food Recycler), 24 saat içinde gıda atıklarını gübre haline getiren dijital bir mutfak cihazıdır (Resim 1). Oksijen, nem ve ısının doğru kombinasyonu ile yiyecek atıklarını 24 saat içinde parçalayıp doğal gübreye dönüştürmektedir (Belisle, Macro, Tepper, Trimble ve Woznicki, 2017).

\begin{abstract}
Akıllı Tava
Tabanına bir sicaklık sensörü monte edilmiş olan akıllı tava (Resim 2), bluetooth üzerinden kullanıcının akıllı telefonuyla bağlantı kurmaktadır (Mogali, 2015). Uygulama, ürünleri karıştırma, çevirme, içerik ekleme veya ısı ayarını değiştirme gibi durumlar için kullanıcıya talimat vermektedir. Akıllı tava, içindeki sensöre zarar vermeden herhangi bir gaz veya elektrikli ocakla da çalışabilmektedir. Akıllı tava sayesinde istenilen ürünün hangi sıcaklıkta ne kadar süre pişmesi gerektiği öngörülebildiği için ürün istenilen zaman ve ayarda pişmesi sağlanır. Kullanıcı kolaylığı yanında fazla pişirmeye bağlı enerji kaybının da önüne geçilmektedir (Mogali, 2015).
\end{abstract}

\section{Ak1llı Sürahi}

Akıllı sürahi, son kullanma tarihini aşan sütler için, üzerindeki yanıp sönen mavi sensörlerle tüketiciyi uyaracak şekilde tasarlanmış bir sistemle çalışmaktadır (Resim 3). Bozulan sütü, yanıp sönen mavi sensörlerle anlayan tüketiciler olası bir gıda zehirlenmesinden kendilerini korumuş olmaktadır. Bunun yanı sıra, henüz bozulmayan sütün de anlaşılacağından dolayı, süt israfı önlenmiş olmaktadır (Mogali, 2015).

\section{Akıllı Çatal}

Çin'de, çiğnemenin kilo alma hızına etkisini ölçmek amacıyla Jie Li ve arkadaşları tarafından yapılan deneyde 14 obez ve 16 normal kilodaki gencin yemek yeme hızları ölçülmüştür. Yapılan deneyde daha çok çiğnemenin deneklerin daha az yemelerine yol açıp açmadığına, kan şekeri seviyelerini ve hormonlarını etkileyip etkilemediğine bakılmıştır. Sonuç olarak daha çok çiğneyenlerin iştah hormonu "ghrelin"in kandaki seviyesinin düşük olduğu tespit edilmiştir. Aynı zamanda lokmaları $40 \mathrm{kez}$ çiğneyenlere göre, \%12 oranında daha az kalori alındığı belirlenmiştir ve daha çok çiğnemenin sonucunda daha az kalori alındığı tespit edilmiştir (Li, 
Zhang, Hu ve Wang, 2011). Kişinin, çatalı ağzına götürme hızına bakarak tüketiciye uyarı gönderen akıllı çatal (Resim 4), bir lokmanın ideal sayıda çiğnenmesine olanak sağlamaktadır. Yemeği çiğneyen birey çatalı normal hızından daha hızlı bir şekilde ağzına götürürse, çatal titreyerek kişiyi uyarmaktadır. Böylelikle lokmanın, ideal sayıda ve hızda çiğnenip tüketilmesi sağlanmaktadır (Kadomura, Chu, Cheng, Yen, Chen ve Siio, 2013). Akıllı çatal, aşırı yemenin önüne geçerek aşırı gıda tüketiminden kaynaklı israfın da önüne geçebilecek bir dijital teknolojidir.

\section{Akıllı Buzdolabı}

Akıllı buzdolaplarını diğer buzdolaplarından ayıran en temel özellik sahip oldukları ağ bağlantıları ve içermiş oldukları kamera sistemleridir (Resim 5). Bu özellik sayesinde kullanıcı dışarıdayken bile dolabının içinde hangi malzemelerin olduğunu kontrol ederek alışverişini buna göre yapabilmektedir. Hizlı ve tempolu hayat tarzının artmasına bağlı olarak bu tarz teknolojilere olan talebin de arttı̆̆ görülmektedir. Böylece kişiler daha eve gelmeden buzdolaplarındaki gıdaların miktarını ve durumunu takip etme imkânına sahip olmaktadır. Akıllı buzdolaplarının sahip olduğu dijital hafızaya, satın alınan yiyeceklerin tarihleri ve miktarları kaydedilip, stok kontrolü de yapılabilmekte (Likitha, Nagashree ve Shruthi, 2016) böylece aşırı gıda tüketimine bağlı israf da önlenebilmektedir.

\section{Akıllı Yumurta Saklayıcısı}

Yumurtanın \%12'sini kabuğu, \%30'unu sarısı, \%58'ini beyazı oluşturmaktadır. Sarı kısmındaki bölüm 'chalaza' olarak adlandırılan bir zar tarafından çevrelenmektedir. Chalaza zarı aynı zamanda yumurtanın altındaki hava boşluğunu oluşturmaktadır. Yumurta tazeliğini yitirmeye başladığında yumurtanın içindeki bu hava boşluğu büyüyüp, yumurtanın yapısında bozulmalar meydana gelmektedir (Tayar ve Yıbar, 2013). Yumurtanın yapısındaki bozulmalar gözle görülemediği probleminden yola çıkılarak akıllı yumurta saklayıcısı geliştirilmiştir. Akıllı yumurta saklayıcısı içerisine yerleştirilen yumurtalardan en önce tüketilmesi gereken yani en bayat olan yumurtanın yanında mavi bir sensör yanıp sönmektedir (Resim 6). En eski yumurta her çıkarıldığında, bir sonraki en eski yumurtanın yanındaki ışık yanıp sönmeye devam etmektedir (Spivey, 2015).

\section{Akıllı Telefon Uygulamaları}

Bir gıdayı israf etmek demek, aynı zamanda tarladan sofraya gelene kadar bir ürünü yetiştirmek için gerekli enerji ve iş gücünü de israf etmek anlamına gelmektedir. Bu bakımdan gıda israfını tüketici temelli engellemek en az endüstriyel atıkların azaltılması kadar önemlidir. Gıda atıklarının oluşumunu engellemeye yönelik bazı platformlar oluşturulmuş ve dijitalleşen dünyada akıllı telefon uygulamaları sayesinde bu platformlara ulaşım oldukça kolay hale gelmiştir. Gıda israfını engellemeye yönelik oluşturulan platformlar ve akıllı telefon uygulamalarından bazıları bu bölümde incelenmiştir.

\section{Blue Apron}

Blue Apron haftalık olarak, tarifi ile birlikte bir yemeği pişirmek için gerekli tüm malzemeleri tartılmış ve hazırlanmış bir şekilde kullanıcıya gönderen Amerikan menşeili bir yemek hizmet sitesidir. Aynı zamanda, malzeme israfı yapmadan, pişirmek istenilen yemeğin nasıl 
hazırlanacağını tarif eden sanal bir şeftir. Blue Apron sitesinden istenilen tarif seçilip adres bilgileri girildikten sonra, gerekli tüm malzemeler tartılmış ve hazırlanmış bir şekilde kullanıcıya gönderilmektedir. Ayrıca yemeklerin kişi sayısına göre seçilen tarifler sayesinde ne kadar sürede hazırlanacağı öngörülerek zamandan kazanç sağlanması yanı sıra yeteri kadar malzeme kullanımı sağlanarak gıda israfının da önüne geçilmektedir (McCarthy ve Schwartz, 2018).

\section{Gram Evde}

Blue apron ile aynı mantıkla çalışan bir diğer firma ise Türkiye menşeili Gram evdedir. Gram evde müşterilerine malzemelerin en yerelini, tazesini ve mevsimine en uygununu seçip, tartıp ambalajlayarak hizmet vermektedir. İsraf ve alışverişe harcanan zamanı ortadan kaldırdığı için de mutfakta sürdürülebilirliği sağlayan bir diğer platformdur (www.gramevde.com).

\section{Too Good To Go}

Too Good To Go akıllı telefon uygulaması ile restoran, market, fırın gibi perakende işletmelerinin ellerinde kalan, yenilebilir durumda olan fakat o gün satılması muhtemel olmayan gidaların ihtiyaç sahiplerine ve daha ucuz gıda tüketmek isteyen insanlara ulaştırılması amaçlanmıştır. Şu ana kadar milyonlarca kullanıcıya sahip olan To Good To Go uygulaması tonlarca gıdanın çöpe gitmek yerine değerlendirilmesi suretiyle $\mathrm{CO}_{2}$ gazı emisyonu azaltılmasını sağlamıştır (Haar ve Zeinstra, 2019).

\section{No Food Waste}

Son kullanım tarihi yaklaşan ürünlerin, ihtiyaç sahiplerine ulaştırıldığı bir platformdur. Too Good To Go ile aynı mantıkla çalışan No Food Waste uygulaması sayesinde arz fazlası gıda ürünleri gönüllü çalışanlar tarafından ihtiyaç sahiplerine ulaştırılmaktadır. Tüketiciler bu uygulamayı kullanarak en yakın birimle iletişime geçip ellerindeki kullanılabilir durumda olan fazla gıdayı yetkililere ulaştırabilmektedir. Güncel rakamlarla şu ana kadar 974.219 kişiye ulaşılıp tam 321 ton gıdanın çöpe gitmesinin önüne geçilmiştir (www.nofoodwaste.org).

\section{Food Cloud}

Food Cloud uygulaması, arz fazlası ürünler ile bu ürünleri talep edenler arasındaki bağı kuran bir yardımlaşma platformudur. Bir mağaza, market ya da işletme, satamayacağını anladığı yiyeceklerin miktarını ve bilgilerini akıllı telefonlar vasitasıyla android uygulamaya yükleyebilmektedir. Bu uygulama yardım kuruluşları ve aracılar arasında iletişim kurmaktadır. Restoran ya da gida işletmeleri ellerinde paylaşmaya hazır yemeklerin olduğuna dair aracı kişilere uygulama sayesinde bildirim göndermektedir. Bildirimi alan aracı kişiler yiyecekleri teslim alıp, ihtiyaç sahibi kişilere ulaştırmaktadırlar. Şu ana kadar milyonlarca öğün ihtiyaç sahiplerine ulaştırılmış olup, bu uygulama sayesinde tonlarca $\mathrm{CO}_{2}$ gazı salınımının önüne geçilmiştir (Weymes ve Davies, 2018).

\section{Yo No Desperdicio}

Atıkların başka evlerde kullanılabileceği ve diğer insanlar için faydalı olabileceği fikri ile yola çıkan Yo No Desperdicio uygulaması, bugüne kadar pek çok insana ulaşmıştır. Tüketilmeyen 
gıdalarının ihtiyaç sahiplerine ulaştırılmasını sağlayarak gıda atıklarını azaltıp, sosyal dayanışmayı desteklemektedir. Benzer diğer uygulamalar gibi Yo No Desperdicio uygulamasının da temel amacl, yiyecekleri çöp kutusuna gitmekten kurtarmak ve en makul şekilde kullanılmasını yaygınlaştırmaktır (www.yonodesperdicio.org).

\section{GIDA BANKALARI}

Dijital mutfak aletleri ve uygulamalarının yanı sıra, adil gıda dağılımı yoluyla sürdürülebilir bir sistem oluşturulmasının en bilinen yolu yardımlaşma ve dayanışmadan geçmektedir. Bu noktada gıda bankası sistemleri oluşturularak gıda dağılımındaki adaletin sağlanması ve atıkların azaltılmasına yönelik bazı tedbirler alınmıştır. Gıda bankacılığı sisteminin temelini The Global FoodBanking Network (GFN) ağı oluşturmuştur. Küresel gida bankacılığı ağı açlık ve israfa yer vermeyen bir gelecek kurmayı amaçlayan ve hâlihazırda 30'dan fazla ülkede üyesi bulunan bir sivil toplum kuruluşudur (Riches, 2018). Gıda bankacılı̆̆g ilk kez 1967 yılında Arizona eyaletinde John Van Hengel tarafından oluşturulmuştur. Hengel, bir tarafta son kullanım tarihi yaklaşmış ya da ambalajı hasar gördügü için atılan gidalar ve diğer tarafta yoksulluktan çöp karıştıran insanlar arasındaki çelişkiye dikkat çekmek istemiştir. Bu çelişkiden yola çıarak yakın çevredeki üretici ve marketlerle iletişime geçip ihtiyaç fazlası, hasar görmüş ya da son tüketim tarihi yaklaşmış ürünleri, kendi çabalarıyla oluşturduğu gıda bankasına yatırmalarını teklif etmiştir. Böylece etkisi bugüne ulaşan bir yardım dalgası başlatılmıştır. Gıda bankalarının bugünkü durumuna bakıldığında, dünya genelinde 30.000 'e yakın gıda bankasının, 6,5 milyon kişiye 540 bin ton gıda dağıtımı sağladığı görülmektedir (Riches, 2018). Böylece açlık ve adaletsiz gıda dağılımının önüne geçmenin yanında gıda israfının önlenmesi suretiyle sürdürülebilirliğe de katkı sağlanmaktadır.

\section{YEŞİL RESTORANCILIK}

Gıda sürdürülebilirliği konusunda en çok vurgu yapılan konu yerel tüketimdir. Yerel yiyeceklerin tüketiminin hem yerel ekonomiyi canlandırdığı hem de yiyeceklerin sofralara gelene kadar çeşitli işlemlerden geçmesi sonucu doğada oluşturduğu karbon ayak izi tahribatını azaltabileceği ifade edilmektedir. Nitekim yerel yiyeceklere olan farkındalığın artması sonucu, tüketicilerin çevreye dost gıdalara yönelmesi ile organik beslenme bir trend haline gelmiştir (Sims, 2009; Jang, Kim ve Bonn, 2011).

Dünya genelinde, ticari ve endüstriyel işletmelerin sebep olduğu sera gazı emisyonu ve atıklardaki artışta, gün geçtikçe büyüyen restoran işletmelerinin payı büyüktür (Kozak, Keser, Büken ve Zaimoğlu, 2019). Gıda sektörü içerisinde oldukça yüksek bir ekonomik potansiyeli bulunan restoranlarda kullanılan gıdaların miktarı, nereden temin edildiği, hangi şartlarda üretildiği, nasıl servis edildiği gibi konular sürdürülebilirlik açısından büyük önem taşımaktadır. Restoran ve catering işletmelerinde kullanılan temizlik ve dezenfektan maddelerin çevreye olan etkileri, üretim sırasında kullanılan ve ortamın idame ettirilmesi için harcanan enerji ve su, uzak mesafelerden yapılan tedarik, ambalaj atıkları gibi etkenler yiyecek-içecek sektörünün doğa üzerindeki etkilerinin boyutunu gün geçtikçe arttırmaktadır (Erdoğan, 2017).

Restoranların karbon ayak izini azaltma ve sürdürülebilir üretim yöntemlerine geçişlerini sağlamak amacıyla Türkiye dahil birçok ülkede yeşil restorancılık oluşumu ortaya çıkmıştır. İşletmelerin yeşil restoran sınıfına dahil olabilmesi belirli şartlara tabi tutulmuştur. Bu şartlar ülkeden ülkeye değişmekle birlikte temelde sürdürülebilir ve doğa dostu üretim modellerinin uygulanmasına yönelik tedbirleri içermektedir (Çetinoğlu, Mesci ve Mesci, 2017). Belirlenen şartları sağlayan işletmelere "yeşil restoran" sertifikası verilmektedir. Türkiye'de restoran 
endüstrisindeki üretimin tüm aşamalarını daha sürdürülebilir hale getirmek ve bu dönüşüme öncülük etmek adına Boğaziçi Üniversitesi ve WWF-Türkiye (Dünya Doğayı Koruma Vakfı) ortaklığıyla "Yeşil Nesil Restorancılık" sertifikasyon sistemi oluşturulmuştur (Pekküçükşen ve Yiğit, 2019). Yeşil Nesil Restoran sertifikasına sahip olan restoran işletmeleri doğa üzerindeki olumsuz etkilerini azaltmanın yanında tüketilen yakıt, su, ekipman, malzeme, tedarik ve atık masraflarından da tasarruf ederek maliyet çıktılarını uzun vadede azaltmaktadır. Tüm yeşil nesil restoran sertifikasyon programlarının ortak prensibi kar amacı gütmeden sürdürülebilirlik için kamuoyunun dikkatini çekmek ve sektöre öncülük etmektir. Yeşil restorancılık hareketi ile sürdürülebilir ve doğa dostu ürünler ile işletme yöntemleri tercih edilmektedir. Bu restoranlar aynı zamanda doğal ve yeşil olanı tercih etme eğiliminde olan müşteri kitlelerinin ihtiyaçlarına da cevap vermiş olur (Erdoğan, 2017).

İngiltere'de 2010 yılında hiçbir kâr amacı gütmeden iki restoran sahibi, iki sürdürülebilirlik uzmanı ve elli kurucu üyeyle kurulan Sustainable Restourant Association (SRA) bünyesindeki yeşil restorancılık standartlarını uygulayan 800 'ü aşkın üyesi arasında iş yeri kantinlerinden Michelin yıldızlı restoranlara kadar pek çok kuruluş bulunmaktadır (Doğan, Nebioğlu ve Demirağ, 2015).

Amerika'da bulunan diğer bir yeşil restoran sertifikasyon sistemi ise Green Restaurant Association (GRA) kuruluşu bünyesinde oluşturulmuştur. GRA öncülüğündeki Amerika'daki yeşil restorancılık hareketi birçok restoranın bilim temelli sertifika standartlarına dayanarak işletilmesini teşvik etmektedir (Şimşek ve Akdağ, 2017). GRA standartlarının amacı, her bir restoranın çevresel başarısını ölçmek ve çevresel sürdürülebilirliklerini arttırmaya yönelik adımlar atmaktır. ABD Çevre Koruma Ajansı'nın (EPA) verilerine göre ABD'deki ticari/kurumsal su kullanımının yaklaşık yüzde 15'i konaklama işletmeleri ve yiyecek servisi işletmelerinden kaynaklanmaktadır. Su verimliliğini arttırmak, atıkları azaltmak, etkili bir geri dönüşüm sistemi oluşturmak bu kuruluşun temel amaçlarındandır.

Türkiye'de çok yaygın olmayan yeşil restoran sayısının artmasının ülke ekonomisine önemli katkılar sağlayacağı düşünülmektedir. Masa örtüsü kullanımının terk edilmesi, bez peçeteler yerine geri dönüşüm kâğıtlardan elde edilen peçetelerin kullanımı, son durulama suyunun ilk yıkama suyu olarak tekrar değerlendirilmesi gibi basit tedbirler restoranlarda önemli tasarruf etmenleri olabilmektedir. Restoran endüstrisi önemli bir elektrik tüketicisi konumundadır. Enerji maliyetleri, tipik bir ticari binanın yıllık bütçesinin yüzde 30'unu temsil etmekte, restoranlarda ise bu miktar ortalama iki katına çımmaktadır. Mutfaklarda kullanılan aletlerin enerji tasarruflu olması, fırınların ve ocakların akıllı sistemlerle donatılması, aydınlatmada tasarruflu ampullerin kullanımı, restoranların doğaya vermiş olduğu hasarı azaltabilecek önlemlerdir (Freeman, 2011). Enerji tasarrufu dışında restoranlar için tedarik edilen gidaların ambalajlarında depozitolu veya geri dönüşümü mümkün olan malzemelerin kullanımı restoran işletmelerinde sürdürülebilirlik için elzem önlemlerdendir (Özdoğan, 2016). Bu bakımdan Avrupa'da özellikle birçok restoran işletmesi devlet politikalarından kaynaklı olarak geri dönüştürülmüş ambalaj malzemeleri ile tedarik yapmakta ve gün sonunda işletmelerinde oluşan her tür atığı takip etmektedir.

Restoran mutfaklarında sürdürülebilirliği sağlamanın en önemli adımlarından biri de yerel olanı kullanmaktır (Freeman, 2011). Bir gidanın yemek olarak tabakta yer alabilmesi için ortalama 2414 km yolculuk yaptığı bilinmektedir (Özdoğan, 2016). Bu bakımdan yöresel olarak satın alınıp kullanılan bir üründe ulaşım maliyeti büyük oranda ortadan kalkmaktadır. Gıda üretiminin sağladığı istihdam ve desteklediği tarımsal faaliyetler ekonomiye önemli katkılar sağlamaktadır (Gustavsson, Cederbeg, Sonesson, Otterdijk ve Meybeck, 2011; Axelos vd., 2018). Kullanılan gıdaların yerel olması iç ekonomiyi desteklediği gibi, gıda tedarik süresini de azaltmaktadır. Ürün sevkiyatına ayrılan maliyetin azalmasının yanında yöresel ürünlerin bir diğer tercih nedeni ise, suları ve toprağı kirletmeyen geleneksel üretim modellerinin bu yolla desteklenmesidir. 


\section{SLOW FOOD AKIMI (YAVAŞ YEMEK AKIMI)}

Slow food akımı özellikle son 30 yıldır dünya genelinde popülerleşen fast food restoranlarına ve hızlı yaşam tarzına doğrudan bir tepki olarak 1986 yılında Carlo Petrini'nin girişimiyle kurulmuştur (Lackova ve Rogovska, 2015). Yok olma tehlikesiyle karşı karşıya kalan yöresel gıdaların üretiminin desteklenmesi amaciyla oluşturulan Slow Food Presidia Projesi sayesinde (Nistoreanu, 2020) geleneksel üretim sistemleri desteklenip, üretimi azalan gıdaların hayatta kalmasına yardımcı olunması amaçlanmaktadır. Slow food akımının temel amaçlarından biri de gıda sistemindeki yozlaşma ve bozukluklar sebebiyle zarar gören bioçeşitliliğge dikkat çekmektir (Pezzana, Bersani, Baldereschi, Ponzio, Frighi, Durelli, Vassallo ve Petrini, 2014). Gidaların mevsimine uygun olarak ve doğal yollarla üretilmesi, bioçeşitliliğin korunması yanı sıra ithal ürünler yerine yerel malzeme kullanımının desteklenip teşvik edilmesi, slow food akımının ana hedefleri arasında yer almaktadır (Şahin ve Kutlu, 2014). Slow Food Presidia Projesi yok olma tehlikesiyle karşı karşıya kalan ürünü, ürünün üretildiği bölgeyi, ekosistemi ve geleneksel üretim yöntemlerini korumayı hedeflemektedir (Pezzana vd., 2014; Yiğit ve Doğdubay, 2017).

Slow food felsefesi yemeğin kalitesini iyileştirmenin ve yenilen yemekten zevk duyulmasının, yemeğe ayrılan zamanla ilişkili olduğunu savunmaktadır (Malatesta, Weiner ve Yang, 2005). Buna rağmen dünya genelinde hızlı yeme içme alışkanlığı olan fast food kültürü bu felsefenin tam tersi bir akım olarak yüksek bir popülariteye sahiptir. Geleneksel mutfakların kendilerine has özellikleri, üretim yöntemleri ve tüketim alışkanlıkları küreselleşen dünyada kaybolmaya yüz tutmuş kültürel değerler haline gelmiştir. Sayılarının azlığına rağmen varlığını sürdürmeye çalışan geleneksel restoranların korunmasını hedefleyen bu akım, yöreye özgü yemeklerin yine yöreye özgü bir atmosferde tüketilmesini teşvik etmektedir. Slow food akımı, yiyecek-içecek sektöründe yerel çiftçiler ve üreticiler ile iş birliği yapılarak yerel ve geleneksel olanı desteklemek suretiyle hizmet verilmesini amaçlamaktadır. Böylelikle hem iç pazarda hareketlenme sağlanacak hem de yerel malzemenin korunması ve sürekliği desteklenecektir. Yüksek üretim hacmine sahip fast food zincirlerinden kaynaklı ekolojik zararlar önlenerek sürdürülebilir üretim yöntemleri desteklenecektir (Kadıŏlu, 2019).

\section{BIYYOGAZ ve KOMPOST ÜRETIMİ}

Yiyecek-içecek sektöründeki gıda atıklarını değerlendirmenin pek çok yolu vardır. En bilinen yolu da artan yemeklerin ihtiyaç sahipleriyle ya da hayvan barınaklarıla iletişime geçilerek değerlendirilmesidir. Bunun dışında biyoyakıt üretimi gibi gıda atıklarının değerlendirilmesi için geliştirilmiş alternatif uygulamalar da mevcuttur (Çelen, 2018). Biyoyakıtlar, bitkilerden, ticari, evsel ve/veya endüstriyel biyolojik kökenli atıklardan üretilebilen yenilenebilir enerji kaynaklarıdır (Hatunoğlu, 2010). Restoran mutfaklarından çıkan organik atıkları biyoyakıt çeşitlerinden biyogaz olarak değerlendirmek mümkündür. Biyogaz organik kökenli maddelerin anaerobik ortamda çeşitli mikrobiyel faaliyetler ile kullanılmasıyla elde edilmektedir (Denizsel, 2007). Biyogazın içeriğindeki metan gazının seviyesine bağlı olarak biyogazı mutfaklarda, aydınlatmada, doğal gaz, su ısıtma gibi amaçlarla kullanmak mümkündür (Minnesota Department of Commerce State Energy Office, 2003). Buzdolabı, döküm çelik veya emayeden üretilen ocaklar gibi birçok mutfak ekipmanında biyogaz kullanılabilmektedir (Painuly, Rao ve Parikh, 1995). Restoran ve catering mutfaklarında oluşan gıda atıklarının tekrar geri dönüştürülerek anaerobik ortamda çeşitli mikrobiyel faaliyetler sonucu biyogaz olarak değerlendirilmesi, işletmelerin kendi enerji ihtiyaçlarını kendilerinin karşılaması, gıda üretiminde sürdürülebilirlik adına önemli gelişmelerdir. 
Restoran atıklarını değerlendirmenin bir diğer yolu da kompost üretimidir. Kompost üretimi, mikroorganizmaların gida atıklarındaki organik maddeleri, ortamdaki oksijeni kullanarak biyokimyasal yollarla ayrıştırması ve toprak için verimli olan humus benzeri bir maddeye dönüştürmesi işlemidir (Eskicioğlu, 2013). Otel veya restoran mutfaklarında büyük oranda organik kökenli atık meydana gelmektedir. Bu atıkların komposta dönüştürülerek tarımda gübre olarak kullanılması, gübrede dışa bağımlılı̆̆ı azaltması yanında toprağın tarımsal ilaçlar sebebiyle kirlenmesine bağlı olarak uzun vadede verimsizleşmesi gibi olumsuz çevresel etkilerin de önüne geçilmesi yönünden önemlidir. Biyogaz ve kompost üretimi sürdürülebilir gıda sisteminin amacına hizmet eden iki önemli alternatif yol oluşturmaktadır.

\section{ÜÇ BOYUTLU (3D) GIDA YAZICILARI}

Tiptan, mekaniğe hemen hemen her alanda kullanılan üç boyutlu yazıcılar gıda sektörünün de faydalandığı yenilikçi teknolojiler arasındadır. Sürdürülebilir beslenmeye yönelik gıda tüketim alışkanlıklarının değişimi küresel anlamda son yıllarda önemli bir gündem maddesi olmuşken üç boyutlu gıda yazıcıları bu gündemin ana teması haline gelmiştir (Pitayachaval, Sanklongand ve Thongrak, 2018). Yemek hazırlamayı dijital çağa taşıyan 3D gıda baskısı, gıdayı kişiselleştirilmiş veya standart bir şekilde üretmek için geliştirilmiştir. 3D gıda baskısı ile çok çeşitli şekiller, dokular ve dekorasyonlar oluşturulabilmektedir. Modellerin yardımıyla karmaşık tasarımlara veya dekorasyona sahip yiyecekler elle hazırlanmasından daha kolay ve standart şekilde hazırlanabilmektedir (Singh ve Raghav, 2018). 3D gıda baskısı çeşitli lezzetlerde artizan ürünler sunabilen ve tamamen veri odaklı çalışan otomatik bir yiyecek hazırlama yöntemidir. Zamanla teknolojik ve sosyolojik gelişmelere bağlı olarak bu teknoloji sağlıklı ürünlerin seri halde üretimine imkân sağlayacaktır (Singh ve Raghav, 2018). 3D gıda yazıcılarıyla aynı zamanda kişiye özel üretim söz konusu olabildiği için özel beslenme programına ihtiyaç duyan bireyler için de faydalı olacağı düşünülmektedir.

Chicago'da yer alan 'Moto' adında bir suşi restoranında şef Cantu 3D gıda yazıcısından faydalanarak insanlardaki yiyecek algısını değiştirmeyi amaçlamıştır. Restoranında balık içermeyen suşiler, mısır nişastası ya da soya fasulyesinden hazırlanan yenilebilir kâğıda basılarak misafirlerin beğenisine sunulmaktadır. Üç boyutlu yazıcının gelecekte, çeşitli tatlar ile aromalandırılmış hap boyutunda hazırlanan yemek ve yenilebilir özellikteki çeşitli kalıplar üreten bir pişirme cihazı olarak kullanılabileceği ifade edilmektedir (Spence, 2018). 3D gıda yazıcıları bilgisayar destekli bir teknoloji olduğu için işçilik maliyetlerini büyük oranda azaltmaktadır (Hod ve Kurman, 2012). Aynı zamanda tüketici isteği doğrultusunda üretim söz konusu olduğu için, özelleştirilmiş gıda üretimine olanak tanımaktadır. Zamanla teknolojik ve sosyolojik gelişmelere bağlı olarak bu teknoloji sağlıklı ürünlerin seri halde üretimine imkân sağlayacaktır (Singh ve Raghav, 2018).

Kişiye özel menü taleplerinin gündemde olduğu günümüzde, üç boyutlu gida yazıcılarının kullanımına ilişkin potansiyelin de bu bağlamda arttığı görülmektedir. Özellikle hammadde kayıplarının azalması ve standart üretim için önemli bir adım olan üç boyutlu gıda yazıcılarının yakın gelecekte daha geniş bir pazar payına sahip olacağı düşünülmektedir.

\section{TARTIŞMA SONUÇ ve ÖNERILER}

Sağlıklı bir yaşam döngüsü ancak doğal kaynakların verimli ve doğru kullanımı ile gerçekleşebilir. Orman arazilerinin yok edilmesi, sera gazlarının atmosferde oluşturduğu hasar ve buna bağlı olarak meydana gelen iklim değişikliği, insanoğlunun sürdürülebilir bir döngü 
içerisinde yaşamasını tehdit etmektedir. Gerek ekonomik gerekse ekolojik yönden pek çok faydası olduğu bilinen sürdürülebilirlik birçok ülkenin önemle üzerinde durduğu bir konu haline gelmiştir. Sürdürülebilir uygulamalar, yiyecek- içecek sektörü başta olmak üzere diğer pek çok işletmeye uzun vadede hayatta kalma imkânı sağlamaktadır.

Dijitalleşen dünyada yiyecek-içecek sektörü için etkili enerji kullanımına dayalı pek çok yenilikçi ürün geliştirilmiştir. Bunun yanı sıra geliştirilen akıllı telefon uygulamaları ile ihtiyaç fazlası olan veya satılamayan gıdaların ihtiyaç sahiplerine ulaştııılması sürdürülebilirlik için etkili bir rol oynamaktadır. Toplumsal dayanışmayı artııran akıllı telefon uygulamaların yanı sıra gıda sektöründe çığır açan 3D yazıcılar müşteriye özel yemek hazırlanması ve etkili malzeme kullanımına imkân sağlamaktadır. Ayrıca 3D yazıcılar, hazırlanması karmaşık gibi görünen yiyeceklerin el değmeden standarda uygun şekilde gereksiz malzeme kullanımını da önleyerek üretim yapılmasını sağladığından zamandan, iş gücünden ve malzemeden tasarruf sağlamaktadır. Yenilikçi teknolojiler sayesinde gıda tasarruf mekanizmalarının evlerin mutfaklarına kadar gelmesi sürdürülebilirlik konusunda önemli bir noktaya gelindiğini göstermektedir. Gıda atıklarından evde saatler içerisinde gübre yapabilmeye imkân tanıyan cihazların üretilmesi sürdürülebilirlik için çı̆̆ır niteliğinde bir gelişmedir. Tüm önlemler ve teknolojik gelişmelere rağmen özellikle de Türkiye'de yiyecek-içecek sektörü için kat edilmesi gereken çok uzun bir yol vardır. Devlet yaptırımları yanında kamuoyu desteği ve baskısı ile egıda, restoran ve catering işletmeleri için ambalaj kaynaklı atıkların sıfırlanmasına yönelik basit ama etkili tedbirler ile yüksek hacimdeki ambalaj kaynaklı atık oluşumunu önlemek mümkündür.

Gıda sürdürülebilirliğine ilişkin yürütülen pek çok çalışma, teknolojik gelişme ve uygulamaların öneminin vurgulandığı bu çalışmada irdelenen tüm bu bilgiler ışı̆̆ında yiyecek içecek sektöründe sürdürülebilir sistemler ve uygulamaların yaygınlaştırılması ile mevcut durumun iyileştirilebileceği ve gelecek için daha umut verici bir hal alabileceği düşünülmektedir. Bu çalışma ile vurgulan bilgiler gelecekte gerçekleşebilecek sürdürülebilir teknolojilerin kullanımı ve yaygınlaştııılması çalışmalarına ışık tutma potansiyelindedir.

\section{KAYNAKÇA}

Atrek, B. ve Madran C. (2017). Tüketici Perspektifli Sürdürülebilir Tüketim Çalışmaları: Ulusal Alanyazındaki Çalışmalar Üzerine Sistematik Derleme Çalışması. Pazarlama ve Pazarlama Araştırmaları Dergisi, (19): 1-31.

Axelos, M., Basinskiene, L., Darcy-Vrillon, B., Ruyck, H. D., Pou, A. M., Salaseviciene, A. and Huttunen, M. (2018). Assessment of Research and Innovation on Food Systems by European Member States. Standing Committee on Agricultural Research (SCAR) Strategic Working Group on Food Systems.

Bazilian, M., Rogner, H., Howells, M., Hermann, S., Arent, D., Gielen, D., Steduto, P., Mueller, A., Komor, P., Tol, R. and Yumkella, K. (2011). Considering the Energy, Water and Food Nexus: Towards an Integrated Modelling Approach, Energy Policy, 39(12): 7896-7906.

Belisle, G., Macro, K., Tepper, M., Trimble, D. and Woznicki, J. (2017). Gateway to Rethinking Organic Waste Business Plan. National Academy of Engineering Grand Challenge Scholars Program. Syracuse, NY.

Çelen, E. (2018). Pastörizasyon Ön İşleminin Biyogaz Üretim Verimine Etkisi. Yayınlanmış Yüksek Lisans Tezi, İstanbul Teknik Üniversitesi Enerji Enstitüsü. İstanbul. 
Çetinoğlu, D. Mesci, Z. ve Mesci, M. (2017). Yeşil Nesil Restoranların Uygulanabilirliğine Yönelik Bir İnceleme: Akçakoca Örneği. Journal of Recreation and Tourism Research, 4 (Special Issue 1): 112-120.

Chapin, F.S., Torn, M.S. ve Tateno, M. (1996). Principles of Ecosystem Sustainability, American Naturalist, 148(6): 1016-1037.

Chatterjee, J. M., Kumar, R., Khari, M., Hung, D. T., and Le, D. N. (2018). Internet Of Things Based System For Smart Kitchen, Engineering and Manufacturing, 4: 29-39.

Coff, C., Korthals, M. and Barling, D. (2008). Ethical Traceability and Informed Food Choice. Researchgate, (15): 1-18.

Denizsel A. (2007). Biyogazdan Elektrik ve Isı Üretimi. Biyoyakıtlar Ve Biyoyakıt Teknolojileri Sempozyumu Bildiriler Kitabı, TMMOB Kimya Mühendisleri Odası. 12-13 Aralık, 2007. Ankara ss: 81-84.

Doğan, H., Nebioğlu, O and Demirağ, M. (2015). A Comparative Study for Green Management Practices in Rome and Alanya, Restaurants from Managerial Perspectives. Journal of Tourism and Gastronomy Studies, 3 (2): 3-11.

Erdoğan, T. (2017). Yiyecek İçecek İşletmelerinde Yeşil Mutfak Kalitesinin (Y-Mutkal) Ölçülmesi: Nevşehir İlinde Bir Araştırma. Yayınlanmış Yüksek Lisans Tezi, Nevşehir Hacı Bektaş Veli Üniversitesi Sosyal Bilimler Enstitüsü. Nevşehir.

Eskicioğlu, A.V. (2013). Bitkisel Atıklardan Kompost Gübre Üretim Sisteminin Tasarımı. Yayınlanmış Yüksek Lisans Tezi, Namık Kemal Üniversitesi Fen Bilimleri Enstitüsü. Tekirdağ.

Freeman, E. M. (2011). Restaurant Industry Sustainability: Barriers and Solutions to Sustainable Practice Indicators. Arizona State University.

Gowdy, J. M. and Mcdaniel, C. N. (1995), One World, One Experiment: Addressing the Biodiversity-Economics Conflict", Ecological Economics, 15(3): 181-92.

Guo, B., Zhang, D., Wang, Z., Yu, Z. and Zhou, X. (2013). Opportunistic IoT: Exploring the Harmonious Interaction Between Human and The Internet of Things. Journal of Network and Computer Applications, 36(6), 1531-1539.

Gustavsson, J., Cederbeg, C., Sonesson, U., Otterdijk, R., and Meybeck, A. (2011). Global Food Losses and Food Waste- Extent, Causes and Prevention. Food and Agriculture of the United Nations (FAO).

Haar, S. and Zeinstra, G.G. (2019). The Impact of Too Good To Go On Food Waste Reduction at The Consumer Household Level: An Explorative Study. Food, Health and Consumer Research VLAG.

Haller, S. (2010). The Things In The Internet Of Things. ResearchGate, 5(8): 26-30.

Hatunoğlu, E. E. (2010). Biyoyakıt Politikalarının Tarım Sektörüne Etkileri. T.C. Başbakanlık DPT Uzmanlık Tezleri İktisadi Sektörler ve Koordinasyon Genel Müdürlüğü, Ankara.

Hod, L. ve Kurman, M. (2012). Fabricated: The new world of 3D printing. Wiley Publications.

Hong, S., Kim, D., Ha, M., Bae, S., Park, S. J., Jung, W. and Kim, J. E. (2010). An Ip-Based Wireless Sensor Network Approach To The Internet Of Things. IEEE Wireless Communications, 17(6):34-42. 
https://blog.teknopusula.com/samsung-family-hub-2-0-akilli-buzdolaplari-5233/ [24.04.2019]

https://gramevde.com/ [Erişim: 20.08.2019]

https://the-gadgeteer.com/2016/02/07/pantelligent-smart-frying-pan-because-bluetooth/ [Erişim:23.09.2019]

https://thegadgetflow.com/portfolio/egg-minder-smart-egg-tray/ [Erişim:23.09.2019]

https://thesra.org/ [Erişim:20.08.2019]

https://www.instructables.com/id/IoT-Bakery-Smart-Bin [Erişim:21.08.2019]

https://www.nofoodwaste.org/ [Erişim: 28.11.2019]

https://www.sabah.com.tr/teknokulis/haberler/2013/06/24/akilli-catal-gercek-oldu

[Erişim:23.09.2019]

https://www.thegreenhead.com/2012/07/milkmaid-smart-milk-jug.php

[Erişim:23.09.2019]

https://www.whirlpoolcorp.com/turning-food-scraps-into-fertilizer-zera-food-recyclerby-wlabs-launches-on-indiegogo/ [Erişim:30.03.2020]

https://yonodesperdicio.org/ Erişim: [20.08.2019]

Jang, J.Y., Kim G.W. and Bonn, M.A. (2011). Generation Y Consumers' Selection Attributes and Behavioral Intentions Concerning Green Restaurants. International Journal of Hospitality Management, 30(4), 803-811.

Kadıŏ̆lu, B. U. (2019). Küreselleşmeyle Artan Fast Food ve Küreselleşmeye Karşı Slow Food. Akademik Sosyal Araştırmalar Dergisi, 7 (95): 204-213.

Kadomura, A., Chu, H.-H., Cheng, K., Li, Y., Yen, A., Chen, C. and Siio, I. (2013). Sensing Fork and Persuasive Game for Improving Eating Behavior. Ubi Comb'13, Zurich, Switzerland.

Kalemdar, G. (2017). Mutfak ve Teknolojik Tasarımların "Akıllı Mutfaklar" Bağlamında Incelenmesi. Yayınlanmış Yüksek Lisans Tezi, Haliç Üniversitesi Fen Bilimleri Enstitüsü. İstanbul.

Keleş, R., Hamamcı, C. ve Çoban, A. (2009). Çeore Politikası. İmge Yayınları, Ankara.

Kiritsis, D. (2011). Closed-Loop Plm for Intelligent Products in The Era of The Internet of Things. Computer-Aided Design, 43(5): 479-501.

Kozak, M., Keser, D., Büken, M. E. ve Zaimoğlu, Z. (2019). İklim Değişikliği İle Mücadelede Soframızdaki Yiyeceklerin Karbon Ayak İzi. International Symposium on Advanced Engineering Technologies. ss: 920-925.

Lackova, A. ve Rogovska, V. (2015). From Slow Food To Slow Tourism. ResearchGate. 1-7 Li, J., Zhang, N., Hu, L. and Li. Z. (2011). Improvement In Chewing Activity Reduces Energy Intake In One Meal And Modulates Plasma Gut Hormone Concentrations In Obese And Lean Young Chinese Men. American Journal of Clinical Nutrition, 94(3). 709716.

Likitha, Nagashree and Shruthi. (2016). IoT Smart Fridge International Journal of Advanced Research in Electronics and Communication Engineering (IJARECE), 5(4): 1136-1139. 
Malatesta, S., Weiner, S. and Yang, W. (2005). The Slow Food Companion. Bra, Italy: Slow Food. 1-49.

McCarthy, D.M. and Schwartz, E.D. (2018). Blue Appron: Turning Around the Struggling Meal Kit Market Leader. WDI Publishing. Michigan Ross School of Business. 177-309.

Minnesota Department of Commerce State Energy Office. (2003). Minnesota's Potential for Electricity Production Using Manure Biogas Resources Final Report. Minnesota Department of Commerce State Energy Office. Minnesota.

Mogali, D. S. S. (2015). Internet of Things And Its Role In Smart Kitchen. ResearchGate. 111.

Nistoreanu, P. (2020). New Trends and Opportunities for Central and Eastern European Tourism. The Bucharest University of Economic Studies. Romania.

Özdilek Dölekoğlu C., Gün, S. ve Giray F. H. (2014). Yoksulluk ve Gıda İsrafı Sarmalı, XI. Ulusal Tarım Ekonomisi Kongresi, 3-5 Eylül 2014. Samsun. ss: 172-182.

Özdoğan, O. N. (2016). Yiyecek İçecek Endüstrsinde Trendler II. Detay Yayıncıllk, Ankara.

Painuly, J.P., Rao, H. and Parikh, J. (1995). A Rural Energy-Agriculture Interaction Model Applied to Karnataka State. Energy, 20(3): 219-233.

Pekküçükşen, Ş. ve Yiğit, Y. (2019). Atık Yönetimi'nde İyi Uygulama Örneği: Yeşil Nesil Restoran Hareketi. Turkish Studies Economics, Finance, Politics, 14 (1): 121-139.

Pezzana, A., Bersani, L., Baldereschi, F., Ponzio, R., Frighi, Z., Durelli, C. P., Vassallo, D. and Petrini, C. (2014). An "LCA" Approach to Slow Food Presidia Products: From AgroEnvironmental and SocioCultural Aspects to Economic Sustainability and Nutritional Evaluations. 9. International Conference LCA of Food, 8-10 October 2014, San Francisco, USA.

Pitayachaval, P., Sanklongand, N. and Thongrak, A. (2018). A Review of 3D Food Printing Technology. Matec Web of Conferences. 1-5.

Pontıng, C. (2008). Dünyanın Yeşil Tarihi: Çevre ve Büyük Uygarlıkların Çöküşü. (Çev.) A. Başçı, Sabancı Üniversitesi Yayınları, İstanbul.

Riches, G. (2018). Food Bank Nations. Routledge. NY.

Şahin, İ. ve Kutlu, S. Z. (2014). Cittaslow: Sürdürülebilir Kalkınma Ekseninde Bir Değerlendirme. Journal of Tourism and Gastronomy Studies, 2(1): 55-63.

Salomone, M. (2014). Sustainability. In: Alex C. Michalos (Ed.), Encylopedia of Ouality of Life and Well-Being Research, New York, London: Springer Dordrecht Heidelberg, 19241926.

Sarıkoca, E. ve Daşlı, Y. (2016). Yoksulluğun Dünyada ve Türkiye'de Seyri. Uluslararası Sosyal Araştırmalar Dergisi, 9(43): 1298-1309.

Sims, R. (2009). Food, Place and Authenticity: Local Food and Sustainable Tourism Experience. Journal of Sustainable Tourism. 17(3): 321-336.

Şimşek, N. ve Akdağ, G. (2017). Sürdürülebilir Gastronomi Turizmi Kapsamında Yeşil Nesil Restoranların İncelenmesi. The Journal of Academic Social Science Studies, 60: 351-368.

Singh, P. and Raghav, A. (2018). 3D Food Printing: A Revolution in Food Technology. Acta Scientific Nutritional Health, 2(2): 11-12. 
Spence, C. (2018). Gastrophysics: The New Science of Eating. Penguin Books, New York.

Spivey, D. (2015). Home Automation For Dummies. John Wiley and Sons, Inc., Hoboken. New Jersey.

Tayar, M. ve Yıbar, A. (2013). Hayatın Kaynağı Yumurta. Yumurta Üreticileri Merkez Birliği.

United Nations. (2018). Special Report: Global Warming of $1.5^{\circ} \mathrm{C}$. [Online] https://www.ipcc.ch/sr15/ [Erişim Tarihi: 23.04.2020].

Weymes, M. and Davies, A. R. (2018) Disruptive Technologies? Scaling Relational Geographies Of ICT-Mediated Surplus Food Redistribution, Sharecity Working Paper 3, Trinity College Dublin.

Yavuz, A. (2010). Sürdürülebilirlik Kavramı ve İşletmeler Açısından Sürdürülebilir Üretim Stratejileri. Mustafa Kemal Üniversitesi Sosyal Bilimler Enstitüsü Dergisi, 7(14): 6386.

Yeni, O. (2014). Sürdürülebilirlik ve Sürdürülebilir Kalkınma: Bir Yazın Taraması. Gazi Üniversitesi İktisadi ve İdari Bilimler Fakültesi Dergisi, 16(3): 181-208.

Yiğit, S. ve Doğdubay, M. (2017). Destinasyon Pazarlama Sürecinde Presidia Ürünlerin Etkisi. Journal of Recreation and Tourism Research, 4(1): 9-48.

Yücenurşen, M. (2019). Rekabet Avantajı Ve Maliyet Minimizasyon Aracı Olarak Doğrudan Pazarlama. Journal of Social and Humanities Sciences Research (JSHSR), 6(46) :3942-3951. 
EK-1

Bazı akıllı mutfak ekipmanlarına ait görseller.

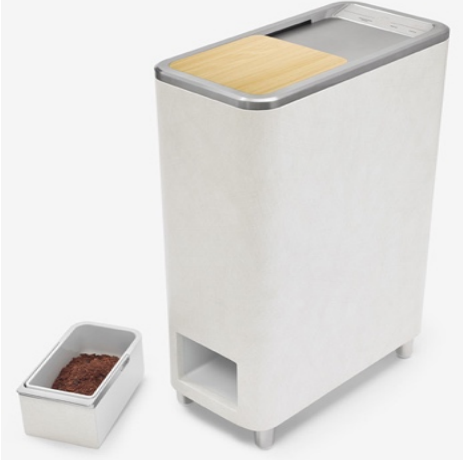

Resim 1: Akıllı Öğütücü

Kaynak:

(www.whirlpoolcorp.com)

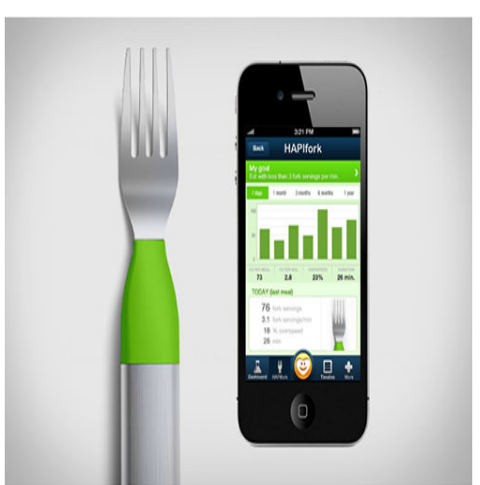

Resim 4: Akıllı Çatal

Kaynak: (www.sabah.com)

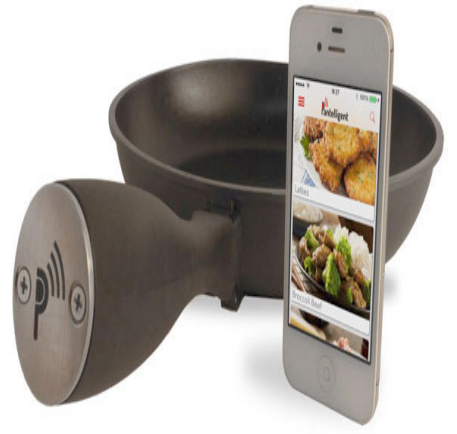

Resim 2: Akıllı Tava

Kaynak: (www. the- 1 . . - .......
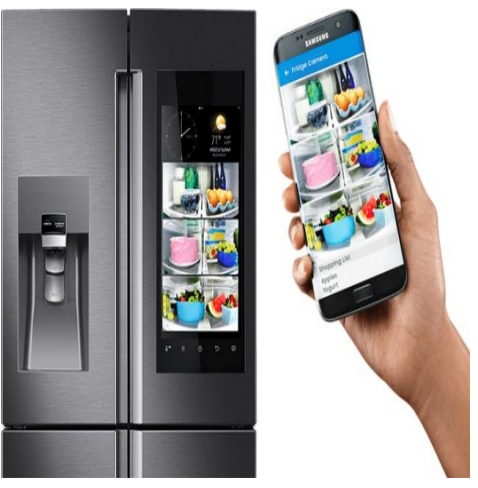

Resim 5: Akıllı Buzdolabı Kaynak:

(blog.teknopusula.com)

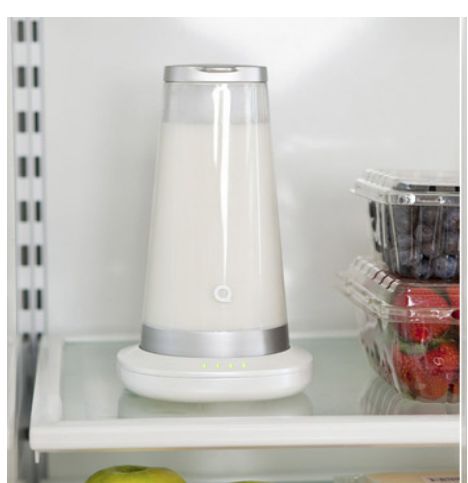

Resim 3: Akıllı Sürahi Kaynak:

(www.thegreenhead.com)

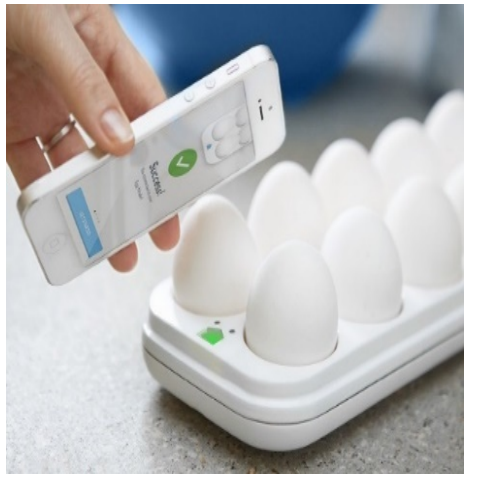

Resim 6: Akıllı Yumurta Saklayıcısı

Kaynak: (www.thegadgetflow.com) 